Putting Social Context into Text: The Semiotics of E-mail Interaction

Author(s): Daniel A. Menchik and Xiaoli Tian

Reviewed work(s):

Source: American Tournal of Sociology, Vol. 114, No. 2 (September 2008), pp. 332-370

Published by: The University of Chicago Press

Stable URL: http://www.jstor.org/stable/10.1086/590650

Accessed: 29/10/2012 21:49

Your use of the JSTOR archive indicates your acceptance of the Terms \& Conditions of Use, available at http://www.jstor.org/page/info/about/policies/terms.jsp

JSTOR is a not-for-profit service that helps scholars, researchers, and students discover, use, and build upon a wide range of content in a trusted digital archive. We use information technology and tools to increase productivity and facilitate new forms of scholarship. For more information about JSTOR, please contact support@jstor.org. 


\title{
Putting Social Context into Text: The Semiotics of E-mail Interaction ${ }^{1}$
}

\author{
Daniel A. Menchik and Xiaoli Tian \\ University of Chicago
}

\begin{abstract}
E-mail excludes the multiple nonlinguistic cues and gestures that facilitate face-to-face communication. How, then, should interaction in a text-based context be understood? The authors analyze the problems and solutions experienced by a research panel that communicated over e-mail and face-to-face for 18 months, evaluating both kinds of exchanges alongside survey and interview data. Semiotic and linguistic theory is used to expose essential properties associated with the successful communication of meaning in each context. The authors find that e-mail requires the cultivation of new techniques for specifically conveying the "pragmatic information" that connects the meaning of words to their users. Such information is assigned in e-mail through the use of what are termed emphatic, referential, and characterizing semiotic tactics. These tactics are also evident in sustained online interactions studied by other researchers. This theoretical vocabulary represents an alternative to the dominant sociological characterization of e-mail as an inferior substitute for face-to-face interaction.
\end{abstract}

A tradition of sociological scholarship has shown the value of studying failure to understand social life. Festinger, Riecken, and Schachter (1956) examined the maintenance of shared convictions by researching how members of an apocalyptic sect coped after their prophecy failed. Shibutani (1978) studied morale by investigating the absenteeism, insubor-

\footnotetext{
${ }^{1}$ The authors appreciate the feedback of Geoffrey Bowker, Ben Cornwell, James Evans, Gary Alan Fine, Hans Joas, Karin Knorr Cetina, Josh Pacewicz, Maria Porter, Saskia Sassen, Michael Silverstein, Dingxin Zhao, and the audiences at the 2005 annual meetings of the ASA and the Association of Internet Researchers. Several AJS reviewers were especially helpful. For funding and access we also thank the Social Science Research Council. Our greatest debt is to the unnecessarily generous panel for allowing us to experience the project alongside them over the 18 months. Direct correspondence to Daniel Menchik, Department of Sociology, University of Chicago, 1126 East 59th Street, Chicago, Illinois 60637. E-mail: mench@uchicago.edu
}

(C) 2008 by The University of Chicago. All rights reserved. 0002-9602/2008/11402-0002 $\$ 10.00$ 
dination, intergroup violence, and protests within a company of Japanese American soldiers during World War II. Details of these breakdowns revealed fundamental social properties.

Our discussion focuses on the case of a well-known scientific organization that decided to replace occasional meetings of a research panel with ongoing e-mail interaction. The sponsor of the panel sought scholars of contemporary social movements and activists who primarily used information technologies in their work. Sixty applied, and $12(20 \%)$ were selected. These experts all had been involved and interested in the subject of technology and social change, and the organization and participants expected lively e-mail interaction about their current work. The panel members encountered a set of frustrating problems, however, even after a face-to-face meeting they thought would improve interaction online. Vocabulary was misunderstood, tone was unrecognized, and intentions were obscured. Interactions were facilitated only through negative sanctions, repeated efforts, and multiple adjustments. Why, we might ask, did this happen?

This episode captures in microcosm multiple issues involved in the dynamics of an information society. The problems, while new, parallel those motivating Simmel (1921), who placed written correspondence, as well as face-to-face verbal and visual interaction, at the center of his work. Communication was also a prominent theme in American pragmatist thought. Dewey argued that society "exists in transmission, in communication . . . there is more than a verbal tie between the words common, community, and communication" (Dewey 1916, p. 5; emphasis in original). Park, who studied with both Simmel and Dewey, argued that communication was, "if not identical with, at least indispensable to, the cultural process" (Park 1938, p. 191). The study of how meaning is preserved in communication also occupied an essential part of many 20thcentury sociological paradigms, such as ethnomethodology, symbolic interactionism, and conversation analysis.

Despite the initial interest of sociologists in social contact of all types, few have explored interactions that fall into the constellation of forms outside those that occur in face-to-face contexts. Symbolic interactionists such as Horton and Strauss (1957) studied the "parasocial interaction" that occurred between television personalities and their audiences, but this work was subsequently developed by communications researchers interested in studies of "media effects" (Giles 2002). Conversation analysts have, on occasion, examined telephone interactions to identify essential dynamics of summons-answer and openings-closings sequences (Schegloff 2002). But even despite a renewed interest in communication among sociologists of culture (Eliasoph and Lichterman 2003), the discipline's focus remains rooted in face-to-face exchanges. 


\section{American Journal of Sociology}

Sociologists have recently begun to discuss the internet, yet these studies too have rarely analyzed interaction. ${ }^{2}$ This neglect likely stems from the unique context of interaction online-without eye contact, tonal inflections, and the ability to adjust on the basis of ongoing feedback, it is unclear how interaction in this context is possible in the first place. A symptom of this problem is that few methodological tools are available for studying online exchanges; coding schemes for conversation analysis capture the prosodic characteristics retrieved in face-to-face and, occasionally, telephone interaction. Consequently, we know little about how to analyze and interpret the paralinguistic communication cues in e-mail.

Theoretical tools for analyzing online interaction are generally drawn from the study of face-to-face exchanges. ${ }^{3}$ In particular, scholars heavily deploy Goffman's research (e.g., Goffman 1959, 1963, 1983). ${ }^{4}$ Concepts developed in research on face-to-face contexts are used to explain internet communication prima facie, and transcripts of text-mediated interaction are interpreted as similarly representing offline dynamics. Yet communication researchers, having been advised to mine such social scientific theories in order to explain and predict problems in interaction (Kollock 1999), have found these theories inadequate for fully explaining activity online. They claim that difficulties stem from ineffective application of theory to scientific practice; failure is attributed to experimental design, not to interpretive tools (e.g., Ling et al. 2005). Amid this process of theoretical repurposing, the initial enthusiasm of nonresearchers for the potential contributions of the internet to communication in domains such as education, business, and science has concomitantly brought frustration

\footnotetext{
${ }^{2}$ For some of the latest sociological research related to the internet, see Turkle (1995), Cerulo (1997), Fischer (1997), Meyrowitz (1997), Cornwell and Lundgren (2001), DiMaggio et al. (2001), Sassen (2002), Calhoun (2003), Pudrovska and Ferree (2004), Klinenberg (2005), Freese, Rivas, and Hargittai (2006), Wellman et al. (2006), and Griswold, McDonnell, and McDonnell (2007). As e-mail is increasingly used to facilitate communication in place of other mediums, such as the telephone or pencil, we use a lowercase spelling of internet. We believe that its contemporary usage suggests that it should not always be treated as a proper noun, despite the fact that it is usually preceded by the.

${ }^{3}$ The term face-to-face here is necessary to represent what Goffman usually termed simply "interaction" or "the reciprocal influence of individuals upon one another's actions when in another's immediate physical presence" (Goffman 1959, p. 15).

${ }^{4}$ See Miller 1995; Burkhalter 1999; Donath 1999; O'Brien 1999; Wallace 1999; Danet 2001; Williams and Copes 2005; Ellison, Heino, and Gibbs 2006; Gibbs, Ellison, and Heino 2006; Robinson 2007. This is an adumbrated list. It is also common to reference Goffman's work in studies associated with the internet more generally; the most comprehensive edited volume of internet studies is titled The Internet in Everyday Life (Wellman and Haythornthwaite 2002). Schutz's work on face-to-face interaction is applied by Knorr Cetina and Bruegger (2004) and Zhao (2004).
} 
with implementation (see, e.g., Selwyn 2000; Prashantham and Young 2004; Walsh and Maloney 2007).

New theoretical tools are necessary to explain e-mail interaction. The asynchronicity and absence of face-to-face cues in e-mail draw our attention to linguistic and semiotic components that convey meaning in text and that have largely been ignored by sociologists. ${ }^{5}$ Language provides the sole source of communication in e-mail and must be used to accomplish the purposes served by facial, tonal, and gestural cues in offline communication. Semiotics, the study of signs and symbols, allows for the analysis of how meaning is constructed and understood between people. It thus offers a theoretical framework for interpreting how communication is possible outside of the face-to-face context.

We focus on a tradition of semiotics founded by Peirce, basing our analysis specifically on the work of Morris (1938, 1946). A student of Mead, Morris examined how meaning between interactants is preserved in communication. His integration of Peirce's ideas into linguistics is particularly useful for interpreting the paralinguistic components that support interaction in a solely text-based environment. By identifying the semiotic elements that enable or stunt communication online and offline and then combining these ethnographic observations with other forms of data on individuals' interpretations of their own exchanges, we can isolate principles that act as new theoretical tools for explaining how interaction is organized outside of the face-to-face context.

For sociology, then, the enduring puzzle about the e-mail discussion group we described above relates as much to the group members' solutions as to their problems. After all, sociologists have long demonstrated the importance of rapid in-person exchanges for intersubjectivity (e.g., Garfinkel 1967; Drew 2003; Collins 2004). The real puzzle, then, is how the same context can ultimately be used to engage in many of the substantive discussions that failed in early attempts. How can linguistic resources available in e-mail be marshaled to overcome the loss of face-to-face cues deemed so central to interaction?

\section{E-MAIL INTERACTION AND ITS PROBLEMS}

A recent survey finds that $65 \%$ of adult Americans send e-mail messages each day. ${ }^{6}$ Given this level of use, e-mail has been the focus of many

\footnotetext{
${ }^{5}$ A notable exception to the absence of sociological studies that draw from semiotics is Barley (1983), and Emirbayer (1997) has discussed the potential payoff of Peircean semiotics for sociological studies of culture.

${ }^{6}$ Pew Internet and American Life Project, http://www.pewinternet.org (accessed February 19,2008 ).
} 
American Journal of Sociology

experiments in the field of communications. Yet a recent review found that most studies in this tradition solely demonstrate that e-mail differs from other mediums, but the authors of these studies do not cite or produce theory to justify these dissimilarities (Walther, Gay, and Hancock 2005). A common conclusion of these studies, however, is that e-mail interaction is of lower quality than that conducted in face-to-face contexts.

A set of studies of computer-mediated communication focuses primarily on interactants' impressions of e-mail as a medium. Many use the framework of social presence theory, which implies that problems in e-mail arise because it provides a low sense of awareness of an interaction partner (e.g., Short, Williams, and Christie 1976; Rice 1993; Rourke et al. 1999). Others examine the level of "information richness" permitted in e-mail and in face-to-face communication (e.g., Daft and Lengel 1984; Treviño, Webster, and Stein 2000). Social presence theory compares mediums in terms of the level of warmth and "personalness" they support; the information richness approach examines the level of personalization they allow and the number of senses usually involved in interaction (Rice 1992). Both argue that the reduction of contextual, visual, and aural markers in email results in a general drop in the quality of interaction (Culnan and Markus 1987).

A body of social psychological communications research explicitly addresses the content of online interaction in e-mail discussion groups, and this research often emphasizes users' difficulties. Multiple studies report complaints about the limitations imposed by the medium itself (Conner 1992; McCarty 1992). Some argue that e-mail discussion groups are not well suited to discussing or solving intellectual controversies among researchers, as individuals rapidly become unsatisfied with the contributions of others and are reluctant to commit themselves to interaction (Hiltz 1984; Harasim and Winkelmans 1990; Lewenstein 1995). E-mail discussion group participants' concerns over the low quality and unfocused nature of discussion frequently lead them to attribute limited value to the online context for in-depth interaction.

Sproull and Kiesler $(1986,1991)$ suggest an underlying reason for the perceived reduction in quality, arguing that problems in e-mail result from its inability to compel the user to limit the range of subjects and comments she considers appropriate to discuss. Their influential "social context cues theory" is based on the assertion that computer-mediated communication lacks equivalent cues to those available in face-to-face contexts, such as facial expressions, body language, and tone of voice (Kiesler and Sproull 1992). This leads to what they refer to as unregulated behavior in e-mail, which they argue is responsible for the increased number of misunderstandings, extreme reactions, and "irresponsible" activities that occurred in the e-mail discussion group used in an organization they studied 
(Sproull and Kiesler 1986, 1991; Kiesler and Sproull 1992). Other researchers have applied their theory to explain why aggressive and hostile exchanges between communication partners seem increased and why the usual inhibitions that govern interactions with superiors appear lower in e-mail (e.g., Dubrovsky, Kiesler, and Sethna 1991; Lea and Spears 1992; Walsh and Bayma 1996; Cramton 2001). They support Sproull and Kiesler's argument that the lack of face-to-face cues in e-mail creates a psychological state in which social and normative influences have been undermined.

In sum, communication theorists emphasize e-mail's negative effect on interaction quality and assign responsibility to the fact that the communication partner is absent. Researchers make comparisons among mediums by classifying them in terms of level of warmth exchanged, number of senses involved, or number of cues permitted. E-mail is thought to allow less warmth and to employ fewer senses and cues. Social context cues theory claims that these limitations undermine social and normative influences, producing "unregulated" exchanges that would not occur in a face-to-face context.

Since we are often able to communicate successfully online despite the change in context, sociologists must study how this is accomplished. Below we address this problem by presenting our observations of successful and unsuccessful attempts, evidence from participants on their intentions for the interpretation of their messages, and a theoretical framework that interprets how text organizes these social interactions.

\section{DATA AND METHODS}

The first author studied the research organization that coordinated the assembly of panel members from the time of its development in July 2003 until its close in February 2005. Since the organization has a strong international reputation among social scientists and those engaged in mediarelated activism, the request for applications was widely diffused through well-populated e-mail discussion groups and the organization's website (which receives over 10,000 visits per day). It also invited specific wellknown scholars and activists to apply for participation in the group. The 12 who were selected in the three-round process represented organizations and universities of various sizes from six continents. Two-thirds of the participants were native English speakers, and all were fluent. ${ }^{7}$ E-mail was fully available to and used frequently by all.

${ }^{7}$ We compared the high- and low-volume posters according to whether they spoke English as a second language or not. Although not enough data are available for statistical analysis, there was no correlation between native language and propensity 


\section{American Journal of Sociology}

The data from the project were collected from environments unmodified for the purposes of this study. Much research on e-mail occurs in controlled settings (although see Kraut et al. 1998; Kendall 2002), which is valuable for theory testing as it allows complete control over the conditions and characteristics of the groups being investigated (e.g., Yamigishi 1995; Kollock 1998). ${ }^{8}$ Analyzing behavior from social groups in natural settings, however, allows for a longer time frame and a richer environment than is often allowed in the laboratory (Hedstrom and Swedberg 1998; Anthony 2005).

Multiple types of data were collected. First, every e-mail $(N=338)$ was read and double-blind coded according to variation along several dimensions: open-endedness (question or comment), subject (related directly to panel topic or not), whether it received a reply (as indicated in the subject field), intended recipient (if possible to determine), and whether it catalyzed or was formulated in response to a problem. We inductively developed categories of problems and respective solutions from these observations and participants' responses to interviews and open-ended survey questions. ${ }^{9}$ After noticing problems in the e-mail discussions around senders' intentions for message interpretation, we contacted individuals via e-mail to discuss specific online activity. ${ }^{10}$ As most participants reported that they were personally unfamiliar with each other prior to the collaboration, the e-mail discussion group appears to have been the primary medium for initial and subsequent interaction. ${ }^{11}$ Second, two online surveys were administered to collect findings on individual sentiments regarding the project after approximately 5 and 15 months of duration

to post. (The three individuals who contributed most frequently spoke Italian, Spanish, and English, respectively, as a first language.)

${ }^{8}$ The nonexperimental conditions of the study meant that we could not vary the group's composition around factors ordinarily studied by social psychologists, such as leadership, gender, task complexity, and status (e.g., Borgatta, Bales, and Couch 1954; Wheelan and Kaeser 1997; Ridgeway and Smith-Lovin 1999; York and Cornwell 2006). However, our group was less clearly task oriented than those investigated in the group interaction literature, as the participants were drawn together to informally discuss a set of issues important to their fields.

${ }^{9}$ Intercoder reliability levels were high (Cohen's $\kappa=.85$ ) for most categories, and coding conflicts were mediated by a third researcher.

${ }^{10}$ We attempted but were unable to reach several members because they did not respond to e-mails or had changed their address.

${ }^{11}$ Participants were surveyed regarding their use of direct communication with others in the panel. Only three responded affirmatively, and they claimed they used direct communication for purposes unrelated to the project. 
(the average response rate was $90 \%$ ). ${ }^{12}$ Third, a 20-hour midproject meeting with all of the participants was observed by the first author and the proceedings were recorded and transcribed. ${ }^{13}$ Fourth, semistructured inperson interviews were conducted with 10 of the participants to collect information about their experiences with the project.

The population we study is unusual in its openness to e-mail as a medium of communication and its capacity to use it; participants frequently employ sophisticated internet-related tools to organize meetings and other events. ${ }^{14}$ Our study of how the system works under these ideal conditions identifies constraints and develops principles for explaining interaction in other online contexts.

\section{The Project's Trajectory}

Soon after the panel members were chosen and the e-mail discussion group was established, members began requesting feedback on subjects germane to the project. One participant asked how others measured the use of internet resources in public computing centers. Another wondered whether cell phones would be superior to computers for mobilizing their constituencies. A third suggested that it made less sense to purchase computers than to strengthen existing capacities of the nongovernmental organizations that work with movement leaders.

Responses rarely followed these posts, and enthusiasm for the project began to wane. The large number of unreturned messages led the project director to express his dissatisfaction with the progress of the e-mail discussion group. His sentiments immediately drew a series of responses in which members claimed that an offline meeting would catalyze future

\footnotetext{
${ }^{12}$ Questions were pretested through a cognitive interview approach (Winkielman, Knauper, and Schwartz 1991). Where relevant, response options were randomized to mitigate order effects, and bipolar scales were employed. Following Porter and Whitcomb's (2003) findings on the positive relationship between e-mail personalization and survey response rate, we contacted members individually by name and with messages reflecting individual characteristics. To reduce measurement error, the first possible answer in "drop box" questions was concealed (Couper et al. 2004), and graphics were used sparingly in order to minimize download time (Dillman et al. 1998).

${ }^{13}$ In analyzing the data, we were conscious of the politics of transcribing complicated visual and vocal events to the printed page (Schieffelin and Doucet 1992; Goodwin 1994). We sought to record elements that captured our source of variation-i.e., the consequences of the use of different kinds of cues across contexts.

${ }^{14}$ Members of the panel are highly literate users of e-mail: $75 \%$ subscribe to at least five other e-mail discussion groups, $67 \%$ contribute to these at least once a month, and $50 \%$ "provide assistance to the work of others" in e-mail discussion groups at least once a week.
} 


\section{Message type}

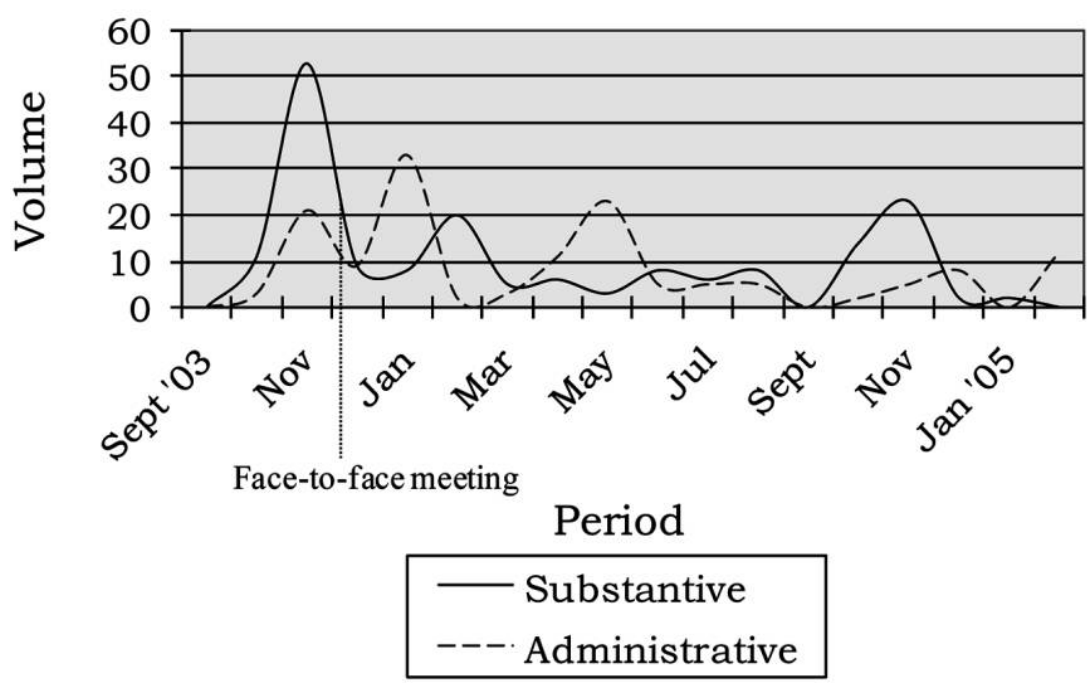

FIG. 1.-Volume of e-mail messages over the duration of the project, by type

posts online. See figure 1 for a description of the volume and type of messages for the duration of the project.

The meeting occurred three months after the project began. Participants came to the meeting optimistic about its value in sparking substantive interaction around common interests. Their confidence was not misplaced; in the face-to-face meeting they seamlessly discussed subjects ignored online. Individuals contributed expertise and their own experiences in response to others' ideas and freely challenged perspectives. They needed no moderator, and subgroup exchanges continued through the lunch break. Participants interviewed at this meeting said it improved their trust and respect of others in a way they thought difficult to accomplish online but necessary for lubricating future e-mail interactions.

Despite the success of the meeting in supporting interaction around subjects initially broached in the e-mail discussion group, it only minimally catalyzed e-mail discussion (see fig. 1). Findings from a survey conducted the following February demonstrate that participants' reported desire to respond to e-mails had not changed relative to feelings expressed prior to the meeting, and in the following three months, the quantity of messages declined by approximately $25 \%$. The expectation of a positive effect of face-to-face interaction upon sustained e-mail interaction was mistaken. To understand the origin of the group's difficulties, we must examine their primary problems and solutions. 


\section{Semiotics of E-mail Interaction}

The Problems and Solutions

A number of distinctions between offline and online interactions were problematic for participants or consistently appeared to present difficulties from an observer's viewpoint. These problems were useful in that they often provided clues for identifying unique characteristics of interaction in the online context. Three primary dynamics influencing attempts to discuss similar subjects across contexts were inductively exposed: problems with terminology, problems of relevance, and problems with situational and background ambiguity. In this section we present how these dynamics were experienced, as well as how participants adjusted to each of them.

Terminological problems.-Members of the interdisciplinary group repeatedly encountered and discussed terminological ambiguity. A sequence of three exchanges effectively demonstrates how each context offered different options for specifying the meaning of a sentence or its components, in addition to different capabilities for negotiating problems of meaning.

In an early e-mail, a participant called attention to the definition of a term frequently used by group members. ${ }^{15}$

$>$ I am curious when we use this term 'civil society' if it is overly generalising a specific set of actors.

Let me quickly illustrate this using the example of 'government' as an actor: often the Treasury in the UK has opposing views from the Home Office, who are often opposed in the Commons by backbenchers, with differing opinions presented by the House of Lords, etc. So I am always hesitant to use the term 'and the UK Government wants . . .'

So when we speak of consulting with 'civil society', or 'giving civil society a seat at the table', or 'civil society organisations are calling for . . .', I wonder if we are being overly generious to these specific organisations, giving them a larger hat than they deserve; or perhaps we are lacking analytical rigour and not looking specifically at what these specific groups want.

That's really what my point was; I am not calling for some definition of what an NGO is; I'm calling for scrutiny of blanket statements to see what the mess beneath is that is being concealed.

This e-mail attracted no responses. Indeed, the entire thread of discussion around civil society ended.

Such linguistic clarification of key words proceeded differently in the subsequent offline meeting.

Chi-Chen: First we must discuss the dichotomies we keep using. For in-

${ }^{15}$ A single arrow indicates that the following material is quoted from an e-mail message. Double arrows $(\gg>)$ are frequently inserted by authors (or their e-mail programs) to indicate that they are quoting from a previous message. Typographical and grammatical errors remain in quoted e-mails in order to reproduce the group's conventions. 


\section{American Journal of Sociology}

stance, Asia's place in a so-called North/South divide is not clear.

Victor: And also, a shared physical presence does not always mean a shared point of view. We just assume this to be true.

Cindy: This language is not a geographical division nor an ideological division. In many cases, northern NGOs identify with the global South. Yet there are different problems in Asia than there are in Africa.

Pat: North/South, developed/underdeveloped, poverty/richness are all frameworks for new complex situations.

Gustavo: All classifications and language are loaded with power disparities. In this case, isn't capitalist accumulation the real thing?

Although participants never agreed on the meaning of the "North/South" dichotomy, they understood one another and easily negotiated concerns about ambiguity when meeting face-to-face.

But what occurred when panel members renewed their efforts at substantive collaboration in e-mail? Here we present an exchange in which they briefly experimented with communication among a smaller group of four individuals as a response to their premeeting difficulties. Each had written a summary of their work, and they collectively sought an approach to combining these into a larger piece to ultimately publish on the sponsoring organization's website.

$>$ I am not sure this works too well and coherently. I don't intend to sound didactic but I think it would appear plagiaristic to reproduce large amounts of text of an already written and published piece-even if only published online-without clearly acknowledging the earlier publication or version...

Pat

Victor replied to Pat with anger and indignation over his tone and word selection. ${ }^{16}$

$>$ Plagiarist? I am not sure how you can use this term when we are expected to be joining papers together? Wasn't that the purpose of this group effort? Also I am only referencing material that you have listed in your paper. In my books plagiarist is a term used for when people copy others people work and give them no credit for it. Which in this case is not the case, as you are not the original thinker in a lot of the material and your name is listed on the paper itself!

I propose that we talk on the telephone to discuss next steps forward. . . . Let me know a good time and numbers to call. Or whether just to call it off.

Pat's subsequent response to Victor exposes his frustration with being unable to communicate the meaning he associated with his words. He

${ }^{16}$ All names have been changed. 


\section{Semiotics of E-mail Interaction}

specifically draws attention to the importance he places upon the use of quotation marks.

$>$ Here is my response and correction on the sensitive issue of plagiarism. I knew this term COULD be offensive and I tried, obviously unsuccessfully, to carefully choose my words. I wrote "I think it would appear plagiaristic" (though I failed to put the word 'plagiaristic' in quotes as I had intended). A careful reading of this, I believe, is that I am not absolutely certain and I am not calling Victor a plagiarist as he seems to imply, rather I am directing the possible 'appearance' of plagiarism to other (third party) readers-at [the research organization] or visitors to its website.

It seems I assumed too much. I was taught at my university that borrowing material substantially from one piece of essay or work and reusing it in another (even though it is still the same person's work) is grouped under plagiarism penalties. In other words, in this context I too would be party to any possible perception of reproducing my already submitted work and re-submitting it; and not acknowledging its earlier publication would foreground this 'appearance of plagiarism' even more. So this was as much an introduction of a point of discussion as it was a pointer to possible 'dangers'. That's the long explanation of it; whether it clears the misunderstanding I leave it to you.

Victor amiably accepted Pat's explanation.

$>$ I am hoping that you can add to the present piece either plagiarising (kidding :-) ) or adding a new piece.

Pat's renewed confidence in the group's capacity to collaborate indicates that the conflict was ameliorated by Victor's extension of goodwill.

$>$ Thanks for the reconciliatory tone. I favour bringing to the joint paper a different piece-along the lines of Cindy and Stefan's contributions-and I can do this in the next few days, hopefully before the weekend. I am hoping that you will be willing to work on the joint piece again; I will try to help with this. At the end, we will remember it's been a long and torturous journely.

The final three messages here contained two frequently used forms of adjustment. First, Pat used capital letters and quotation marks to place special emphasis on particular points. He felt that this allowed him to insert volume and tone into a message communicated via a medium that disallows auditory emphases. Second, Victor sought to annul the prior meaning of the controversial word by accompanying it with an emoticon. ${ }^{17}$

${ }^{17}$ Emoticons are pseudolinguistic sequences of punctuation marks that depict an image of a face (usually smiling). 
American Journal of Sociology

Pat recognized Victor's intention, noting the message's "reconciliatory tone." Although interpretative difficulties between two individuals are usually not so aggressively negotiated, this exchange exposes how the absence of face-to-face cues can influence the way language is interpreted among those who otherwise share much in common and hold a strong interest in working together. ${ }^{18}$

Taken together, these episodes reveal how approaches to managing terminological ambiguity differed across contexts and carried different consequences. The first e-mail demonstrates the difficulty of discussing conflicting meanings online, whereas an analogous offline discussion drew lively interaction. Pat and Victor's e-mail exchange demonstrates how initially divergent interpretations of the purpose and meaning of a word's use can damage relations, as well as the way punctuation and capital letters were thought to be able to clarify senders' intentions for how their messages should be received.

Ambiguities around relevance.-Several of the discussion group's problems stemmed from the disruption of the turn-taking format that characterizes face-to-face conversation (Sacks, Schegloff, and Jefferson 1974). Consequently, it was difficult for individuals to signal to whom their comments were oriented. These problems were indicated in both interviews and reflections expressed in e-mail.

Interviewees repeatedly pointed out problems arising from the asynchrony of message transmission and reply. First, message senders were unsure that others would recognize how their comments were germane to the points they sought to address. Since individuals were not online simultaneously, another member might broach a different subject before the designated recipient of an original post could respond. The resulting crisscrossed threads of conversation increased people's reluctance to post. Second, individuals were frequently unsure of the person or subject to which a point was oriented. People remained silent, despite having substantive and relevant ideas to contribute, as they later asserted, because the eye contact available in offline conversation for designating an intended respondent was unavailable. Participants felt little reassurance that they could orient others' contributions on a topic as they could have in face-to-face exchanges.

One sign of members' powerlessness to establish common subject matter was their feeling that the group did not share enough in common, despite the fact that many of them had researched the same subjects and published in the same outlets. Participants' responses to open-ended survey questions indicate that they felt like their ideas on a subject were not

${ }^{18}$ The smaller group that participated in this e-mail exchange was self-assembled among those who met at the offline meeting. 
worth presenting: "I only post if have something important to say"; "The tone of the list-serv was poorly set. It was created saying: 'Talk amongst yourselves,' and that's all. I'm not too good at that"; "I don't know what we are supposed to talk about here. . . . We were just thrown together to interact."

This perception was further evidenced when participants expressed a need for a shared goal: "Sometimes inventing even a simple goal-e.g. drafting a mission statement or selecting our next meeting place-can get things going"; "The list was a forum, but it didn't have a goal-oriented task, so I never felt an urgency to participate. Other, more urgent tasks crowded it out in my attention"; "You need a specific vibe or purpose for exchange to work, the issue of "civil society and ict [information and communication technology]' didn't provide that in this case."

As mentioned above, participants expressed a desire to have a face-toface meeting after the program director inquired into the low volume of messages. This request was particularly motivated by their belief that a meeting would offer a context facilitating a more focused discussion around common interests.

$>$ I do believe that personal face-to-face contacts still make a difference, in creating and making active something like a netwroks which is bound to work long-distance. I felt positive about this opportunity and would be honoured to develop ways to share ideas and visions.

Louis

>And yes, the face to face is required to start things off. Gustavo

$>$ I think this network will benefit greatly from a face-to-face meeting. . . . For me at least, it will make this activity "real."

Jose

At the meeting, people spoke frequently about many of the topics addressed-and ignored-online. They did not each necessarily respond to the person who preceded them, but rather waited their turn to talk and to claim their share of the attention in the room. The diversity of their backgrounds and lack of a common goal appeared benign.

When they returned to online exchanges, however, a set of techniques emerged that reflected a more relational orientation. First, the author of a message would name the author of the previous one in the body of her message:

$>$ But I also agree with Pat that, together with substance and isssues raised, we should also become more "operative" and concrete. I think in our re- 


\section{American Journal of Sociology}

stricted network meeting we did have some good ideas and I, starting from there, am also throwing a couple of ideas in the air.

>In response to Roger's message today, I venture to share the following intuitive thoughts . . .

$>$ Following from the 'brainstorming type of exercise' recommended by Chi-Chen, I'll try to weigh in. I have to admit that a part of me was still recovering from [the meetings] even when I returned from the holidays, only to start teaching again, but here's my effort.

The informal pressure applied by these "linking" techniques improved substantive continuity in discussions. The referenced persons would respond, sparking a chain of interaction arising out of an initial effort to assert relevance. Interestingly, the response time dropped for messages with these characteristics.

Formally addressing a message to a specific individual similarly improved the likelihood of a response..$^{19}$ Exchanges between two people on project-related subjects were more likely to be sustained than those either without a greeting or with a generic one such as "Dear all" or "Dear colleagues." When participants with messages that were intended for the entire group addressed the project director or the participant whose comment preceded theirs, it appeared to others that the comment was situated within a dyadic interaction rather than framed as a comment or query to the collective. Even then, people were more likely to insert their opinion than if a dyadic exchange had not yet commenced.

Second, people would use others' posts to support their own contributions, choosing to cut and paste from previous e-mails to ensure that the intent of their comments was clearly indicated, as in the following message:

$>$ A very late response. . but possibly in this case not too late. $>$ Let me take advantage of this first communication to throw an idea out there. It seems many of us are doing work that explores specific examples of uses of ICTs by CSOs [civil society organizations]—from content management and open source to wireless PDAs [personal data assistants]. . . . Does it make sense to put to together a casebook that can be used by CSOs to learn about the advantages of "cutting edge" technologies as well as how best to set themselves up to exploit them?

$>$ I have discussed this with my colleague Jane who thinks it can be very useful.

As people occasionally objected to the recontextualization of their

${ }^{19}$ Group members maintained formality in the majority of their e-mails, beginning with greetings and ending with closures such as those used in conventional letters. 
words, this approach did not necessarily resolve problems of relevance. However, it appeared to be a tool through which members felt they could signal the temporal and topical referents of their posts.

In sum, project members initially thought that e-mail was a poor medium for substantive discussion because of both the characteristics of the medium and their own divergent backgrounds. Offline, this diversity was not a problem. Later in the project, relational techniques for signaling the situational relevance of a post were developed and frequently deployed.

Obscured situational and background information.-Finally, participants' inability to draw upon certain information from others' appearances and inflections provided another set of frustrations. The distance made it especially difficult to convey the intention behind an utterance.

In open-ended survey responses, the members of the panel indicated that they were initially reluctant to send e-mail because of uncertainty over whether they could calibrate their post to be received in a certain way: "I don't know how people are going to react"; "[In e-mail, you] don't know who you are talking to."

They were similarly uncertain about whether others would understand the tenor they sought to assign to a message: "[I am concerned about misinterpretation] if the e-mail involves some complicated personal problems, feelings, emotions"; "Conflict was problematic. I'm concerned that people would classify this kind of interaction as severe. Would be seen as flaming." ${ }^{20}$

Participants' concern over being perceived as aggressive was further revealed in their increased tendency to preface comments with disclaimers:

$>$ I don't intend to sound didactic, but . . .

>This may come across harshly, but . . .

Interview and survey responses revealed an acute consciousness of the range of ways a message could be received, and the sender's inability to adjust accordingly: "I don't know if there are common understandings of the message. People essentialize the meaning of comments"; "The costs of developing your message in such a way that you can speak to everyone is too high." Rather than risk misinterpretation and the accompanying anxiety, participants often opted for silence.

Participants gradually developed ways to include certain information

20 "Flaming" refers to "sudden, often extended flare-ups of anger" considered common to online interaction (Danet 1998). It has been reported both in laboratory settings and in a variety of business, governmental, educational, and public networks (e.g., Sproull and Kiesler 1986; Lea and Spears 1992; Thompsen and Ahn 1992). 
American Journal of Sociology

on their cultural background and emotional state in order to influence others' interpretations of their utterances. For instance, they would include details on their frame of mind at the time of posting, closing e-mails with disclosures related to their potential levels of awareness (e.g., "writing at 7 a.m."). Second, in the openings and closings of a message they might use foreign languages to signal an affiliation with a particular culture ("ciao," "colegas"); they might also index their culture in a celebratory gesture ("SELAMAT TAHUN BARU!" "Feliz Año Nuevo"). Finally, they would often place information on their geographic location following their name by using a signature file. ${ }^{21}$ They would also signal if they were currently traveling, attempting to account for their neglect of previous messages and inability to contribute in a fashion consistent with what they felt would otherwise be expected of them. These three techniques provided information that individuals thought would be useful for recipients in decoding the meaning they assigned to a message. They were further used in order to demonstrate interest in participation itself, a means for signaling engagement that would otherwise be difficult to detect in text.

Problems associated with terminology, relevance, and situational and background ambiguity accounted for the failure of the project to meet the expectations of its participants. However, these problems precipitated a set of adaptations to text-based interaction. Below we will argue that situations in which text is the primary medium for communication demand interpretative tools that account for the way language is used to organize interaction. Semiotics and, in particular, its applications in linguistics, offers a lens for understanding the above interaction problems and subsequent adjustments. We should first, however, consider alternative explanations for these problems.

\section{EXPLANATIONS BASED ON INTEREST, COMMITMENT, AND INCENTIVES}

This was a unique project. Panel members had committed to participation and signed a contract to interact online, making the expectations placed on them different from those in a usual face-to-face conference or academic e-mail discussion group. Yet the group composition and interaction formats in our study are commensurable with those in other research on group-based online interaction, allowing us to consider three common

${ }^{21}$ A signature file contains text that follows the end of a message and, once created, is usually appended automatically to postings. The text may include contact information and institutional affiliation, a quote that is meaningful to the sender, or a legal disclaimer. 
explanations for the problems our panel members encountered: the substantive, associative, and strategic arguments.

First, the substantive argument proposes that absence of topical interest might be responsible for the silence and other difficulties with the e-mail discussion. Rheingold (1993) claims that this factor determines issue-based interaction online. He argues that individuals will interact online when they share a common set of interests around a particular topic and are given the opportunity to discuss it.

The conversation topics pursued online were central to the theme of the project and the expertise of participants. Transcripts from the faceto-face meeting demonstrate their personal stake in discussing these subjects. The 12 panel members had dedicated their careers to activism and its analysis, achieving high levels of status within organizations considered to be at the apex of their professions. An analysis of participants' CVS demonstrates that each had dedicated an average of 15 years to research or advocacy around directly related issues. The offline meeting showcased their intimate understanding of the geographic areas with which they worked. Finally, $83 \%$ expressed a desire to engage in future projects on the panel's subject after the official end of the program. These facts make it unlikely that the communication problems can be attributed to disinterest in the issue at hand.

A second explanation might be called the associative argument. Perhaps the group was not committed to working together. According to Weber's (2004) arguments on open-source communities and Kollock's (1999) theories on the public provision of expert knowledge in e-mail discussion groups, online groups will face collective action problems similar to those described by Olsen (1965). These scholars assert that individuals have a disincentive to post to a group discussion, because the rewards from this action will be distributed among recipients. Silence, then, comes from skepticism about the ultimate payoff from participation.

This argument is challenged by our participants' attempts at interaction and the motivations they reported. E-mail transcripts show that individuals found the lack of interaction before and after the meeting problematic. Ninety-two percent of the participants indicated a "very high" or "high" desire to contribute to the e-mail discussion group. A surveyed participant reinforced this: "I had an interest in this network, as I was looking, among other things, for a sound form of continuity [of communication regarding information technology and activism] and I thought this group of people was an interesting starting point." Further, a set of posts that occurred immediately after the meeting indicates interest in continuing discussions initiated offline. And answers to the survey question "How important were the following factors in deciding to apply for inclusion on the project?" also contradict an associative explanation. The $\$ 2,000$ hono- 
American Journal of Sociology

rarium and the status obtained from inclusion in the network were reported as extremely low motivations for application (although such professions of disinterest would be expected from high-status individuals). Instead, survey respondents claimed that they applied for admission in the hopes of discussing the topic of the panel, and $92 \%$ of participants answered that an "interest in engaging with other experts" was their dominant motive for applying for admission to the project.

Finally, reticence to interact might be seen as strategic, explained by a lack of professional incentive. Matzat (2004) argues that this is an important factor in online settings and finds that the desire to cultivate social contacts with other researchers motivates researchers' use of e-mail discussion groups. Consequently, group composition matters. This is similar to Bourdieu's (1984) argument that individuals in academic fields engage with those who offer the greatest professional returns for doing so. These scholars would expect people to be more likely to communicate with other researchers, as they have the most to gain through engagement or lose through inaction.

Table 1 presents reported motivations for e-mail discussion group behavior. Contrary to the expectations suggested by a strategic explanation, we see little connection between disciplinary or professional relationship and decision to respond to a post. If we subscribed to this explanation, we would also expect there to be a strong negative association between the decision to post and a desire to communicate across disciplines. Analysis of transcripts from e-mail discussion group and face-to-face interactions indicates that the sequences of responses among interactant dyads are not more likely to involve successive exchanges among individuals in the same discipline than among those in different disciplines. ${ }^{22}$ And the low importance of personal ties for explaining motivation is not surprising, given the scarcity of preexisting relationships among group members. ${ }^{23}$

It is interesting to note that participants reported time constraints to be relatively influential on their decision to respond to a post. Considering this response as an indication of preferences in light of the opportunity cost of not engaging in other activities (Becker 1965), it suggests that group members felt that crafting an effective e-mail in this situation would require more work than they initially expected (see also Galegher and Kraut 1990). It is possible that this sentiment derives directly from the diverse disciplinary and professional affiliations in the group; the requirements of communicating across linguistic registers likely will produce

\footnotetext{
${ }^{22}$ However, the interpretation of posting sequences is complicated by between-person differences in frequency of checking e-mail.

${ }^{23}$ Note that the even distribution of the interest variable further weakens the plausibility of the substantive explanation discussed above.
} 


\section{Semiotics of E-mail Interaction}

TABLE 1

Reasons for Decisions to Respond to E-MaIl Discussion Group Posts

\begin{tabular}{|c|c|c|c|c|c|}
\hline \multirow[b]{2}{*}{ FACTOR } & \multicolumn{5}{|c|}{ Amount of INFLuence* } \\
\hline & 1 & 2 & 3 & 4 & 5 \\
\hline Discipline of sender & 75 & 17 & 0 & 0 & 8 \\
\hline Profession of sender & 75 & 17 & 0 & 0 & 8 \\
\hline Interest in topic & 25 & 8 & 8 & 25 & 33 \\
\hline Personal ties with sender & 33 & 17 & 25 & 8 & 17 \\
\hline Time available ...... & 25 & 8 & 0 & 8 & 58 \\
\hline
\end{tabular}

Note. - Data are percentages of respondents. Some rows do not add to 100 because of rounding.

* Influence scores range from 1, "not influential," to 5, "extremely influential."

more obstacles in e-mail than in person. ${ }^{24}$ The lack of immediate feedback and the inability to specify how one intends to be interpreted in e-mail may magnify difficulties and increase the time necessary to compose a message.

In this section, we have demonstrated that levels of interest in the subject, commitment to the project, and incentives for participation were all strong in the group we study. And yet these individuals were reluctant to invest the time and energy required to communicate effectively. Survey responses indicate that the demands of addressing the problems presented above could be too high online. These concerns suggest the importance of the semiotic elements we analyze in more detail below.

\section{SEMIOTICS AND COMMUNICATION CONTEXTS}

Peirce (1934) developed modern sign theory, or semiotics, out of the philosophical school of pragmatism. This tradition holds that there is an intrinsic connection between meaning and action; the meaning of an idea is to be found in its "conceivable sensible effects," and humans generate belief through their "habits of action." To Peirce, signs can be words, gestures, objects, or even silence, but they only have meaning in the context of a continuing process of interpretation. A crate used for sitting is thought of as a chair, yet its meaning changes when it is used for storage.

Morris (1938) is known for drawing on Peirce's research to bridge the explanatory gap between the meaning of a sentence to the speaker and its meaning to the receiver. Previous theorists of language (e.g., Saussure 1966) had maintained a structural orientation, assuming these two ele-

${ }^{24}$ We thank Michael Silverstein for suggesting this point. 
American Journal of Sociology

ments to be equivalent. Yet Morris showed that the meaning the speaker and the receiver assign to a sentence are contingent and are linked through a sign system whose elements are specified in the process of interaction.

Morris (1938, p. 33) argued that language comprises signs, which simply "refer to something for somebody." Each sign has three components: the sign vehicle (SV), the designatum (D), and the interpreter (I); SV is a sign of $\mathrm{D}$ for I to the degree that $\mathrm{I}$ takes account of $\mathrm{D}$ in virtue of the presence of SV. To illustrate: a crown (SV) represents royal power (D) for the British people (I).

Semiotics states that an individual sign has become completely characterized when it has given its relationships to other signs, to its objects $(\mathrm{SV}+\mathrm{D})$, and to its users $(\mathrm{SV}+\mathrm{I})$. These three relationships are respectively governed by syntactical, semantical, and pragmatical rules. To continue the above example: syntactical rules indicate the formal relations between the crown and other signs or expressions in abstraction from their signification and their interpreters; semantical rules indicate that the crown signifies power to the English, rather than weakness; and pragmatical rules indicate that the crown signifies power to the English people, but not to the Chinese. These components are reestablished by users on each occasion of communication. We must have information on all these dimensions of a language to understand how it operates.

Morris directed linguists' attention from syntactics and semantics toward pragmatics, which emphasizes that the meaning a speaker assigns to a sign must be expected by its recipient. Such a shift made the study of context crucial to understanding sign construction. To Morris, context refers to any linguistic, objective, or subjective factor that affects the actual interpretation of signs and expressions, and it conditions the extent to which a recipient is aware of the speaker's expectations for the interpretation of the sign components she uses. Consequently, to accurately interpret another's sign components a person must account for whether the interaction is occurring in a library or classroom, over the telephone or by e-mail.

Pragmatic information, to Morris, specifically represents the meaning of a sign to its user. As might be expected, communication mediums differently support the transmission of components that signal this information. Individuals have particularly well-developed approaches for defining signs they use in face-to-face interaction, where they rely on cues such as facial expressions and tonal inflections to specify the meaning of a vocally delivered sign in a certain situation. With successful specification, the interpreter is a judge and the sign combination is the judgment. But the components for specifying pragmatic information online are different from those encountered offline, meaning that the development of 
a judgment requires one to cultivate new approaches to expressing oneself and interpreting others' statements in this context. ${ }^{25}$

Panel members' difficulties in communicating over e-mail about the same issues they had discussed more easily at the meeting were a consequence of their inability to communicate pragmatic information within the online context. A shift to e-mail interaction requires a new set of interactional skills to be developed, even among those who are well acquainted in offline contexts. Participants had many of the same problems with substantive interaction online after the meeting as before it, in spite of the interpersonal familiarity they achieved offline, a familiarity that was indicated by the subsequent thank-you notes and professed satisfaction with the trust and respect gained at the office meeting..$^{26}$ Paralinguistic elements used by participants in the online context did not initially support the communication of pragmatic information assigned to others' signs. They needed to know more information on others' physical features, mood, and points of reference in order both to understand their statements and to be comfortable responding.

Our data show how interaction worked in the face-to-face context. The transcript of the conversation on North/South dichotomies illustrates how speakers could assign meanings to specific terms that meeting participants initially defined differently. We saw that one person at the meeting sought to convey that she felt the North/South dichotomy represented a geographic distinction, while another felt it was an ideological one, and a third considered it an embodiment of a form of economic oppression. Background cues could be communicated through appearance alone: when a Chinese woman discussed Asia, the face-to-face setting allowed others to see her ethnicity, which suggested that she expected others to interpret her comment in reference to East Asia. Even though members had different previous associations with these words, the specifying information available when they were face-to-face allowed them to temporarily settle on one set of terms and a provisional definition for the purposes of the discussion. Most important, they understood others' use

\footnotetext{
${ }^{25}$ Over his career, Morris appears to have respecified his terminology for characterizing the expressions to which pragmatical rules apply. He became dissatisfied with the use of the term pragmatical sign, arguing that it makes unclear whether an expression designates a kind of sign or a sign within the part of semiotics distinguished as pragmatics (see Morris 1946, p. 218). Morris never appeared to resolve the issue; our use of the term pragmatic information follows that of later semioticians (e.g., Bach 2004).

${ }^{26}$ The meeting clearly created new collegial relationships. Of the respondents to the postmeeting survey, $75 \%$ indicated that they would be interested in "collaborating on a project or coauthoring with" at least one person from the panel, naming that person specifically ( $92 \%$ indicated that prior to the project they had not personally communicated with the others).
} 
American Journal of Sociology

of the words. Seamless interaction was possible because the recipients of a speaker's statement could develop a plausible interpretation of the meaning that the speaker desired to assign to it.

The possibility of assigning pragmatic information to an utterance explains why individuals freely contributed offline on the subject of the North/South dichotomy. They knew their intentions for interpretation would be understood, as the meeting supported visual and aural communication of sign components that they expected could be interpreted by others. Also, a person could immediately respond if others' cues suggested that his comments had been incorrectly interpreted. At the meeting, Gustavo argued, "All classifications and language are loaded with power disparities. In this case, isn't capitalist accumulation the real thing?" In making his point that economic systems were the most important elements in distinguishing poor and rich countries, he enunciated "capitalist" while looking at individuals from the wealthier nations. In his "reaccentuation" of the word (Bakhtin 1986), he made it clear to all that he was using it in a critical way. The crucial take-away from this episode is the fact that his meaning for this word was understood by all; pragmatic information was comfortably assigned in a face-to-face interaction.

The experience differed in e-mail. The misunderstanding between Victor and Pat exposed several of the group's problems and solutions in attempting to assign pragmatic information. Although Pat did not intend for Victor to interpret his use of "plagiaristic" as an accusation, Victor inaccurately interpreted it as such. Although they are both fluent speakers of English, Victor did not correctly interpret the definition and referent of Pat's remark because he did not recognize the information Pat used to specify how he wanted to be received. Pat then saw that he had been misinterpreted and felt compelled to clarify his intention for the word's meaning in a lengthy exposition. He felt that he could use quotation marks to indicate how he intended the word to be received. Additionally, he used capital letters to express concern that his use of "plagiaristic" "COULD be [seen as] offensive." Victor then assigned new pragmatic information - a "reconciliatory tone"-to "plagiarising" by accompanying the word with an emoticon. The incident demonstrates how interpretations of semiotic components diverge in e-mail, and it highlights the consequent primary importance of pragmatic information to effective communication.

Morris's integration of semiotics into linguistics has enabled us to trace the discussion group's problems in e-mail to their difficulties in communicating and interpreting pragmatic information. Signs are "true" insofar as they correctly determine the expectations of their users and so release more fully the behavior that is implicitly aroused in the expectation or interpretation (Morris 1938, p. 33). When the signs linking the meaning 


\section{Semiotics of E-mail Interaction}

of a word or message to its user are ambiguous among interactants, the possibility of misinterpretation is high and the consequences of miscommunication often costly.

Members of our panel used terms of intention, agency, and volition both to discuss their speech acts and to repair misunderstandings online. Morris's work has allowed us to locate ourselves with the panel and explain how their problems were addressed. It has helped us to solve the more general problem in communication that this article confronts: the way individuals understand what others mean when they say something in e-mail. Our assumption is that meaning in language can be found in the way language expresses peoples' intentions, and thus Morris's approach is adequate for these individuals. But this approach to language is not the only one that can account for the way meaning is communicated in text. In fact, Morris's approach has been criticized for its intentionalist and behaviorist orientation (Hanks 1996). Accordingly, to develop a formal theory of online interaction, we must account for the social structure of a group and the inherent influences of power, gender, and status differences orienting speech acts in any interaction setting (Rosaldo 1982; Duranti 1993). In the next section we demonstrate the affinities of our case with a range of in-depth studies of internet interaction, in order to develop a general classification scheme that can explain how pragmatic information is communicated online.

\section{Semiotic Tactics}

Semiotic tactics helped the discussion group ameliorate many of their initial problems by providing pragmatic information. These tactics served to calibrate the members' use of language in line with the local norms and expectations underpinning relationships in many other online contexts. In this section we classify three varieties of semiotic tactics: (1) emphatic tactics, which enunciate or assign a general tone to particular parts of a message; (2) referential tactics, which specify others' contributions to a message or its intended recipient; and (3) characterizing tactics, which communicate demographic or situational background information that the sender thinks will be relevant to others' interpretations of his message. The typology is analytic: the types are not always empirically distinct. For instance, use of an emoticon can be intended to assign an ironic tone to a word or communicate background information on the spirit with which a person extends a message. Exclamation points may be used for emphasis, but also to signal that the user is actively interested in an interaction. Yet, while these three types intermingle in empirical settings, they each serve distinct purposes for communicating pragmatic information in e-mail. 
American Journal of Sociology

Emphatic tactics call attention to key words or phrases that a sender considers important for understanding the meaning of her message in its entirety. Individuals often use emphatic tactics to specify the tone they want to assign to a particular message. Emoticons can bind an unaggressive tenor to a contribution. Bullet points can replace narrative with a businesslike style. Each of these emphatic tactics is isomorphic, and studies of distributed work demonstrate that conventions for presentation frequently diffuse in interactions where all participants are exposed (Orlikowski 1996; Ackerman et al. 1997; Mark 2002). However, these techniques reflect presentation styles that may initially not be appreciated by recipients: emoticons may be deemed unprofessional in work-related interaction, and the use of bullet points may appear stilted to friends.

Strategic text formatting is an important emphatic tactic, with excessive capitalization or punctuation used to direct the recipient's attention to specific elements of a word in a post. Authors often change the style, size, or color of text to achieve the same effect. Kendall (2002) demonstrates how members of a chat room use capital letters to indicate sarcasm: "I FEEL SO BETRAYED." In another example, she shows that when a chat room participant wrote a capitalized message involving multiple asterisks and exclamation points, it drew the response, "You *are* guilty of overcapitalization," and the member was exiled from the chat room by the moderator (Kendall 2002, p. 174). Such sanctions reveal the importance of emphatic tactics for maintaining norms of conduct in online interactions.

In the plagiarism incident between Victor and Pat, each person believed he could change the tone underlying the exchange. Indeed, the use of quotation marks and capital letters allowed them to neutralize a onceproblematic word and transform it into an inside joke. Considering that Pat was forced to explain what his use of quotation marks meant, however, the episode also shows that emphatic tactics will not be consistently effective if participants diverge in their expectations of the way interaction tone is assigned meaning in text. ${ }^{27}$

Emphatic tactics are especially important when there is disagreement, and rituals are accordingly developed and followed in order to indicate the desire to be considered friendly. To mitigate disagreement online, people use qualifiers that frame disagreements as resulting from innocent differences in perspective. Qualification is a convention that shows a sender's desire to soften others' perceptions of her message as aggressive: "I may be wrong, but I thought . . ." Another tactic used by our group

\footnotetext{
${ }^{27}$ The process through which several recipients may assign different meanings to a message is not unlike the way literary work is received differently across cultures (Griswold 1987).
} 
was to reiterate previous posts, along with an explanation such as "this is what I meant." Finally, there are occasions when intentions are explicitly specified, and comments are prefaced with "I think this is so funny" or "No offense, but . . ." (Baym 1999). Similar performances were observed by Lamerichs and te Molder (2003), who demonstrated that members of an online support group would be sensitive to the proper limits for indicating their depression while continuing to appear supportive in a forum. Members of our group expressed differing opinions at the meeting but were hesitant to disagree online for fear of appearing hostile. Emphatic tactics were used in later attempts to avoid or dampen this kind of interpretation.

Referential tactics assign meaning to a person's own message by specifying other people and past messages that oriented its development. These tactics draw on social ties to clarify the meaning of a post and may be used in the subject line, initial greeting, or body of an e-mail.

A sender will frequently seek to indicate ideas or subjects from others' posts that are germane to her own message. However, the asynchronicity of e-mail demands that she explicitly specify this relevance. Group members used the cut-and-paste referential tactic to isolate and distinguish points they sought to develop. They would also deliberately leave the entire text of a relevant previous post below their contribution, a tactic linguists have shown to create the illusion of adjacency (Severinson Eklundh and Macdonald 1994). Unsurprisingly, this practice has also been shown to increase the chances of accurate message reception (Beenen et al. 2004).

The asynchronicity of e-mail and its lack of visual cues also often disguised a message's intended recipient, complicating interpretation of the elements contributing to the formation and communication of the sender's signs. Sociolinguists have documented how interactants frequently use so-called linking techniques to refer explicitly to the author of a previous message in their response in order to negotiate such referential tracking problems (Baym 1996; Herring 1996a). Lamerichs and te Molder (2003) demonstrated that members of an online support group used the subject field of an e-mail to display pragmatic information that indicated they intended to speak solely to another person with their message, despite the fact that it would be widely received. Users felt that this referential tactic absolved them from accountability for having displayed private notes publicly. Such a transformation of dyadic interactions to one-to-many broadcasts also indicates how the social ties indexed in the "three-way" speech acts among radio personalities semiotically operate in online group interactions (Goffman 1981, pp. 234-35).

We have so far referred only to the way references expressed between members of a group work to clarify pragmatic information in interactions 


\section{American Journal of Sociology}

between individuals. Referential tactics, however, can also endow an authority figure with the power to influence a group's ongoing operation. For instance, the set of messages that expressed support for a face-to-face meeting followed an expression of concern from the program director, who then became the named recipient of subsequent messages. A moderator such as this may be formally or informally nominated, but generally performs several relevant functions. First, he may frequently insist that participants stay on topic, preventing members of an academic group from straying to, for instance, political issues in their discussion. Successful e-mail discussion groups usually have moderators who are vested enough in the group to effectively apply sanctions so that their sentiments will be supported and enforced by others in the group. Second, the moderator often acts as a gatekeeper for the messages that are extended to the group. An individual who then anticipates that her contribution will be censored by the moderator may attempt to craft a message in such a way as to avoid objection. Robinson (2005) shows that posts were selectively edited when members of the news-related chat rooms she studied knew that a moderator was monitoring. As the moderator has the capacity for orienting the discussion such that people craft comments with him in mind, members of such discussion groups do not feel they need a common goal, as was the case in the beginning of our panel members' exchange. In addition to informally controlling the target to which messages are directed, moderators may overtly urge individuals to address the generalized subject matter around which the group has been organized. And given that so-called awareness messages from leaders of work teams have been shown to significantly increase the speed at which group members complete tasks (Weisband 2002), we can see that referential tactics' capacity to convey authority and collegiality has tangible consequences for productivity. ${ }^{28}$

Finally, characterizing tactics provide background and situational pragmatic information that the sender thinks will be relevant to others' interpretation of her message. Panel members crafted their message signatures to indicate both their institutional affiliations and membership in multiple other working groups. These provided alternatives to the visual information available in the offline setting, where interlocutors can use the unstated referents of comments (such as the one regarding Asia above) to contextualize their meaning. Signatures can be used to anchor virtual characteristics in offline ones, as they often include a link to a personal home page with pictures. The signature offers a more robust and reliable

\footnotetext{
${ }^{28}$ The prevalence of such tactics, which resemble verbal citations, suggests the need for future research on the noninstrumental origins of the referential tactics that resemble other genres of communication common to workplaces, such as memo writing.
} 
indicator of identity than is thought to be generally available in text, and it assists respondents with interpreting a message by specifying the writer's other institutional affiliations. It serves a similar purpose as the characterizing tactics participants used in the openings and closings of their messages to signal their language and country.

Panel members also revealed political characteristics through their arguments. For example, Gustavo's criticism of the consequences of global capitalism was consistent with those of other activists in his country. Burkhalter (1999) illustrated a similar phenomenon in his study of online discussions about the use of neighborhood space. Participants in that study found that they were able to detect others' racial or cultural affiliations by looking at whether they framed the germane subject of the group as being related to segregation or business concerns.

A sender often includes information on her physical situation in the hope that others will better understand potential influences on the coherence of her message. In offline contexts, such as a closing session at an academic conference or a conversation after an overnight airline flight, interlocutors will account for the fact that others are not at full capacity, and expectations for the quality of discussion will be adjusted accordingly. To gain such consideration for their online communications, our panel members often included characterizing comments to specify that their message was penned early in the morning or "on their way out the door."

Finally, punctuation can be manipulated to convey situationally bound pragmatic information that pushes the interaction forward. Antaki, Barnes, and Leudar (2005) found that exclamation points were used more frequently by women in online professional forums and argued that these characterizing tactics were strategically used to convey friendliness and an interest in interaction. As language patterns evolved within these forums and participants developed idiosyncratic styles of interaction, others adopted the phrases and abbreviations particular to the community. This occurred as a consequence of the need for symbols to instrumentally convey a message, as well as for text-based impression management.

This typology does not capture the range of potential tactics used to communicate pragmatic information. Furthermore, those we present may not necessarily be effective. By showing the way semiotic tactics work across group settings, however, we have moved beyond the methodological individualism of Morris and sketched a theory that is applicable across online social contexts. Such a theory indicates a way to understand how an individual can use e-mail to "know what the other [is] about and . . . have some way of keeping the other informed as to his own purpose and progress" (Dewey 1916, p. 7). These semiotic tactics also exemplify how people innovate in response to the challenges of a new context for the communication of essential elements of language. 
American Journal of Sociology

DISCUSSION

We have shown that our panel's problems arose in communicating pragmatic information in e-mail and that they addressed these problems with three kinds of semiotic tactics. Below we discuss our contributions to the sociological study of e-mail interaction and sociolinguists' study of linguistic change.

The emphatic, referential, and characterizing tactics we identify indicate the limits of considering online interactions to be unregulated by social context cues. First, we have shown that the absence of aural and visual cues in e-mail did not prevent users from crafting messages with an awareness of their communication partners. Participants clearly were concerned about pragmatic information. They were aware that they needed to reformat their contributions to suit the context and were anxious about their ability to anticipate how their meaning would be interpreted. Uncertainties over potential reception were directly coupled with concern for coherence, leading to silence when others' pragmatic information was obscured. Second, we exposed a logic to the way e-mail messages were formulated. A set of rules, involving the use of capital letters and quotation marks, were cultivated and obeyed in an attempt to promote comprehension. It is indeed possible that online interactants will on occasion feel less inhibited-a person may act more aggressively because of the decreased threat of verbal or physical violence. Yet it is also possible that online actions appear aggressive because the linguistic cues are not fully specified, as was the case in the group we studied. Over time, semiotic tactics emerged as locally cultivated linguistic cues that overcame the problems occurring in earlier stages of interaction. ${ }^{29}$

Similarity between the semiotic underpinnings of face-to-face and email interaction makes it unsurprising that people can cultivate ways of communicating in online contexts that are equally as effective as those used offline. Recent studies of distributed work show that members of teams can become proficient with elements unique to text-mediated asynchronous interaction, such as the extended response lapses and time required to type (Walther 2002). Hancock and Dunham (2001) similarly show that impressions formed in computer-mediated communication can be more intense than those developed offline. Walther's work with colleagues intriguingly demonstrates that presenting information uncommon

\footnotetext{
${ }^{29}$ Considering that people use different cues to organize interaction, however, new logics of stratification may follow efforts to communicate pragmatic information. Behavior unintentionally interpreted as negative or a signature file that is seen by others as strange may stigmatize the sender of an e-mail. Our analysis suggests that more research on this subject can potentially identify emerging cultural origins of stratification, with semiotic tactics representing, e.g., a new set of cues that create or reaffirm status beliefs (Ridgeway and Erickson 2000).
} 
in e-mail (such as pictures) can actually stunt interaction (Walther, Slovacek, and Tidwell 2001). These findings further call into question the presumption about the superiority of face-to-face contexts for interaction, that "the telephone and the mails provide reduced versions of the primordial real thing" (Goffman 1983, p. 2). Although offhanded, perhaps, Goffman's comment is in the spirit of much of the research on computermediated communication discussed in the beginning of this article. Yet our analysis suggests that it is valuable to think of these contexts as supporting a set of independently appropriate approaches to signification, rather than as situations in which the level of interaction quality may be measured on a sliding scale.

By identifying how semiotic tactics are cultivated for a new context, we offer examples of how interaction changes language, moving us beyond the behaviorist core of Morris's work (Hanks 1996). Following Labov (1966, 1994), the study of sociological factors in linguistic variation has become the concern of current mainstream sociolinguists (Gal 1989, 1995; Schieffelin, Woolard, and Kroskrity 1998; Cook 2004). Our study thus contributes to recent efforts in sociolinguistics to understand how language is changing in e-mail communication (e.g., Herring 1996b, 2002; Baron 2000; Crystal 2001; Cassell and Tversky 2005).

Our primary contribution to sociolinguistics involves the identification of semiotic tactics. Linguistic change online can arise from innovative attempts to assign pragmatic information within a context that transforms respective sign components. If new text-based signs are created that denote information similar to that which can be presented offline, e-mail messages can effectively communicate these gestures. For instance, we found that emoticons serve a prescriptive purpose, indicating intentions for interpretation. Most communications scholars argue that these serve to specify the emotional state of the user (e.g., Rice and Love 1987; Thompsen and Foulger 1996; Rezabek and Cochenour 1998). We show, however, that emoticons are frequently used as a semiotic tactic to refine the meaning and tenor that a sender would like to convey with a word or message, seeking to calibrate the word in order to reduce the possibility of its being misinterpreted. As the purpose of these symbols is prescriptive, we should therefore not be surprised to find that emoticons do not induce emotional reactions in their recipients (Walther and D'Addario 2001). Similar to the way Gal (1989) clearly demonstrates how language changes occur in sync with self-presentations that exhibit "modern" characteristics in times of political and economic change, we show that linguistic changes in e-mail can emerge from performative efforts in text-based conversation.

By showing pragmatic information to be specific to a particular communication context, we also support and extend Morris's argument that this information is differently transmitted depending on time and place. 
American Journal of Sociology

Among our study participants, the same level of interpersonal familiarity was not initially felt across face-to-face and online contexts, a finding that contributes to recent work on the subject (Haythornthwaite 2002; Mesch and Talmud 2006). It follows that participants should consider their past experience with interacting with each other in a medium when determining a primary forum for interaction. A relationship with a long online history will likely support an interaction without the breaches described above. But a close friendship offline may not necessarily be experienced as such online. Similarly, it is possible that interactants' different experiences and familiarity with a medium itself will condition their capacity to interpret their partners' use of signs. Generational differences are likely to affect online behavior. The results of our study suggest, however, that the importance of these social characteristics to mutual comprehension will diminish over time. Rather, the degree to which two or more individuals develop unique conventions in the medium will determine their ability to communicate effectively.

The theoretical tools we present can also be used to classify how users and designers are driving shifts in technology itself. The formal and material characteristics of a medium are inseparable from the process of signification it supports. In the appendix, we offer examples of how software designers are accordingly changing the contexts of e-mail and other online settings, expanding the way pragmatic information can be assigned within a text-only interface. ${ }^{30}$ Emergence of these new interfaces illustrates a general point made by scholars of science and technology: that computerrelated tools have evolved alongside the needs of their users (cf. Latour 1987; Bijker 1995; Czarniawska and Sevón 2005). The changing interfaces can expose needs for language presentation that arise from attempts to command another's attention outside the realm of situated copresence. An e-mail conversation read at a desk must compete with other potential foci for a respondent's attention. Further research on the way interfaces command their users' attention can suggest the ingredients for a theory of linguistic change that would explain how text might overcome the other distractions confronting an e-mail recipient.

In the analysis of our empirical case, we primarily emphasize characteristics of participants' speech acts rather than the relational and individual traits of those animating these acts. Yet by also integrating the social characteristics of our respondents into our theory of semiotic tactics, we were able to see how factors such as the norms of an online context and the gender and relational ties of participants were important elements in how subjects communicated pragmatic information in our study and others. Work remains in developing new methods and coding schemes for

${ }^{30}$ See D'Souza (2005) for a sophisticated analysis of the semiotics of interface design. 
detecting how these in potentia characteristics in group settings become converted into semiotic tactics that are successfully interpreted by readers of online speech acts. Further research, then, might also evaluate the influence of these specific social characteristics across face-to-face and online contexts for periods longer than 18 months and distinguish the relative value of semiotic tactics in groups that are deliberately varied according to social characteristics commonly examined by social psychologists.

As with the translation of words into another language, ideas must change forms when expressed across interaction contexts. Statements exchanged face-to-face will be experienced differently when received by email, and semiotic tactics offer an initial vocabulary for characterizing how meaning is communicated across settings. Such an understanding of how context is put into text helps us appreciate the dynamics of one of the recent forms of mediated interpersonal interaction constituting contemporary society.

\section{APPENDIX}

The problem of pragmatic information in e-mail is now being recognized by software designers. Symbols are being added to communication media that assist both the sender's attempt to attach pragmatic information and the reader's ability to anticipate the meaning of a message.

Text-based instant messaging programs are becoming extremely popular. ${ }^{31}$ This software allows users to share pragmatic information in multiple forms: an individual can display pictures of herself on her partner's screen, choose a pictorial background she feels is appropriate for the intended mode or theme of a conversation, or use a web camera to display her facial expressions. These interfaces can even expose the music an interactant is listening to on her computer. Pragmatic information gathered unconsciously in face-to-face situations is increasingly built into the interface.

E-mail programs remain largely text based, but many now respond to users' attempts to apply semiotic tactics. In many e-mail clients, typing : ) will return (-). This automates the specification of word tenor by translating text into more powerful visual stimuli.

Most interestingly, some e-mail programs attempt to protect users from misinterpreting text by preemptively reviewing senders' words. ${ }^{32}$ Profan-

\footnotetext{
${ }^{31}$ Fifty-nine percent of Americans 18-29 years old, and 15\% of adults over age 29, have used these programs, according the Pew Internet and Social Life Survey (Rainie and Horrigan 2005).

${ }^{32}$ The most notable is the MoodWatch feature in the Eudora e-mail program.
} 


\section{American Journal of Sociology}

ities and potentially harsh word combinations such as "I hate you" or "you're paranoid" will activate one of three so-called mood warnings, depending on the level of severity assigned to a message by the program. The three responses issued by the program read, "Better hope you know the person," "Watch out, you're playin' with fire here," and "Your message is the sort of thing that might get your keyboard washed out with soap, if you get my drift. You might consider toning it down." If a response is triggered by the contents of a message, the author will receive it before the e-mail is sent, and the recipient will be alerted before opening the message. The program seeks to train senders to anticipate potential misinterpretations of their messages and to protect recipients by preparing them for messages the program considers to have been assigned a severe tone.

\section{REFERENCES}

Ackerman, Mark S., Debby Hindus, Scott D. Mainwaring, and Brian Starr. 1997. "Hanging on the 'Wire': A Field Study of an Audio-Only Media Space." ACM Transactions on Computer-Human Interaction 4:39-66.

$\rightarrow$ Antaki, Charles, Rebecca Barnes, and Ivan Leudar. 2005. "Self-Disclosure as a Situated Interactional Practice.” British Journal of Social Psychology 44:181-200.

$\rightarrow$ Anthony, Denise. 2005. "Cooperation in Microcredit Borrowing Groups: Identity, Sanctions, and Reciprocity in the Production of Collective Goods." American Sociological Review 70:496-515.

Bach, Kent. 2004. "Pragmatics and the Philosophy of Language." Pp. 463-87 in The Handbook of Pragmatics, edited by Laurence R. Horn and Gregory Ward. Oxford: Blackwell.

Bakhtin, Mikhail. 1986. Speech Genres and Other Late Essays. Translated by Vern W. McGee. Edited by C. Emerson and M. Holquist. Austin: University of Texas Press.

$\rightarrow$ Barley, Steven R. 1983. "Semiotics and the Study of Occupational and Organizational Culture." Administrative Science Quarterly 37:363-99.

Baron, Naomi. 2000. Alphabet to Email: How Written English Evolved and Where It's Heading. New York: Routledge.

$\rightarrow$ Baym, Nancy. 1996. "Agreements and Disagreements in a Computer-Mediated Discussion." Research on Language and Social Interaction 29:315-45.

1999. Tune In, Log On: Soaps, Fandom, and Online Community. London: Sage.

$\rightarrow$ Becker, Gary. 1965. "A Theory of the Allocation of Time." Economic Journal 75: 493-517.

Bijker, Wiebe E. 1995. Of Bicycles, Bakelites, and Bulbs: Toward a Theory of Sociotechnical Change. Cambridge, Mass.: MIT Press.

$\rightarrow$ Borgatta, Edgar F., Robert F. Bales, and Arthur S. Couch. 1954. "Some Findings Relevant to the Great Man Theory of Leadership." American Sociological Review 19:755-59.

Bourdieu, Pierre. 1984. Homo Academicus. Stanford, Calif.: Stanford University Press.

Burkhalter, Byron. 1999. "Reading Race Online: Discovering Racial Identity in Usenet Discussion." Pp. 60-75 in Communities in Cyberspace, edited by Marc Smith and Peter Kollock. New York: Routledge.

Calhoun, Craig. 2003. "Information Technology and the International Public Sphere." 


\section{Semiotics of E-mail Interaction}

Pp. 229-51 in Shaping the Network Society: The New Role of Civil Society in Cyberspace, edited by Douglas Schuler and Peter Day. Cambridge, Mass.: MIT Press.

Cassell, Justine, and Dona Tversky. 2005. "The Language of Online Intercultural Community Formation.” Journal of Computer-Mediated Communication 10 (2): art. 2. http://jcmc.indiana.edu/vol10/issue2/cassell.html.

$\rightarrow$ Cerulo, Karen. 1997. "Reframing Sociological Concepts for a Brave New (Virtual?) World." Sociological Inquiry 67:48-58.

Collins, Randall. 2004. Interaction Ritual Chains. Princeton, N.J.: Princeton University Press.

$\rightarrow$ Conner, Patrick. 1992. "Networking in the Humanities: Lessons from ANSAXNET." Computers and the Humanities 26:195-204.

$\rightarrow$ Cook, Susan. 2004. "New Technologies and Language Change: Towards an Anthropology of Linguistic Frontiers." Annual Review of Anthropology 33:103-15.

$\rightarrow$ Cornwell, Benjamin, and David C. Lundgren. 2001. "Love on the Internet: Involvement and Misrepresentation in Romantic Relationships in Cyberspace vs. Realspace." Computers in Human Behavior 17:197-211.

$\rightarrow$ Couper, Mick, Roger Tourandeau, Frederick Conrad, and Scott Crawford. 2004. "What They See Is What We Get: Response Options for Web Surveys." Social Science Computer Review 22:111-27.

$\rightarrow$ Cramton, Catherine. 2001. "The Mutual Knowledge Problem and Its Consequences for Dispersed Collaboration." Organization Science 12:346-71.

Crystal, David. 2001. Language and the Internet. Cambridge: Cambridge University Press.

Culnan, Mary, and M. Lynne Markus. 1987. "Information Technologies.” Pp. 420-43 in Handbook of Organizational Communication, edited by Fredric Jablin, Linda Putnam, Karlene Roberts, and Lyman Porter. Newbury Park, Calif.: Sage.

Czarniawska, Barbara, and Guje Sevón, eds. 2005. Global Ideas: How Ideas, Objects, and Practices Travel in the Global Economy. Frederiksberg: Liber \& Copenhagen Business School Press.

Daft, Richard, and Robert Lengel. 1984. "Information Richness: A New Approach to Managerial Behavior and Organizational Design." Research in Organizational Behavior 6:191-233.

Danet, Brenda. 1998. "Flaming." Pp. 246-47 in Encyclopedia of Semiotics, edited by Paul Bouissac. New York: Oxford University Press.

- 2001. Cyberpl@y. Oxford: Berg Press.

Dewey, John. 1916. Democracy and Education: An Introduction to the Philosophy of Education. New York: Macmillan.

Dillman, Don, Robert Tortora, J. Conradt, and Dennis Bowker. 1998. "Influence of Plain vs. Fancy Design on Response Rates for Web Surveys." Paper presented at the Joint Statistical Meetings, Dallas, August.

$\rightarrow$ DiMaggio, Paul, Eszter Hargittai, W. Russell Neuman, and John P. Robinson. 2001. "Social Implications of the Internet." Annual Review of Sociology 27:307-36.

Donath, Judith. 1999. "Identity and Deception in the Virtual Community." Pp. 29-59 in Communities in Cyberspace, edited by Marc Smith and Peter Kollock. New York: Routledge.

$\rightarrow$ Drew, Paul. 2003. "Precision and Exaggeration in Interaction." American Sociological Review 68:917-38.

D'Souza, Clarisse. 2005. The Semiotic Engineering of Human-Computer Interaction. Cambridge, Mass.: MIT Press.

$\rightarrow$ Dubrovsky, Vitaly, Sara Kiesler, and Beheruz Sethna. 1991. "The Equalization Phenomenon: Status Effects in Computer-Mediated and Face-to-Face DecisionMaking Groups." Human-Computer Interaction. 6:119-46.

Duranti, Alessandro. 1993. "Intentions, Self, and Responsibility: An Essay in Samoan 


\section{American Journal of Sociology}

Ethnopragmatics." Pp. 24-47 in Responsibility and Evidence in Oral Discourse, edited by J. Hill and J. Irvine. Cambridge: Cambridge University Press.

$\rightarrow$ Eliasoph, Nina, and Paul Lichterman. 2003. "Culture in Interaction." American Journal of Sociology 108:735-94.

Ellison, Nicole B., Rebecca D. Heino, and Jennifer L. Gibbs. 2006. "Self-Presentation Processes in the Online Dating Environment." Journal of Computer-Mediated Communication 11 (2): art. 2. http://jcmc.indiana.edu/vol11/issue2/ellison.html.

$\rightarrow$ Emirbayer, Mustafa. 1997. "Manifesto for a Relational Sociology." American Journal of Sociology 103:281-317.

Festinger, Leon, Henry Riecken, and Stanley Schachter. 1956. When Prophecy Fails. New York: Harper Torchbooks.

$\rightarrow$ Fischer, Claude. 1997. "Technology and Community: Historical Complexities." Sociological Inquiry 67:113-18.

$\rightarrow$ Freese, Jeremy, Salvador Rivas, and Eszter Hargittai. 2006. "Cognitive Ability and Internet Use among Older Adults." Poetics 34:236-49.

$\rightarrow$ Gal, Susan. 1989. "Language and Political Economy." Annual Review of Anthropology 18:345-95.

1995. "Language, Gender and Power: An Anthropological Review." Pp. 153-61 in Gender Articulated: Language and the Socially Constructed Self, edited by Kira Hall and Mary Bucholtz. London: Routledge.

Galegher, Jolene, and Robert Kraut. 1990. "Technology for Intellectual Teamwork: Perspectives on Research and Design.” Pp. 1-20 in Intellectual Teamwork, edited by Jolene Galegher, Robert Kraut, and Carmen Egido. Hillsdale, N.J.: Lawrence Erlbaum Associates.

Garfinkel, Harold. 1967. Studies in Ethnomethodology. Englewood Cliffs, N.J.: Prentice Hall.

$\rightarrow$ Gibbs, Jennifer L., Nicole B. Ellison, and Rebecca D. Heino. 2006. "Self-Presentation in Online Personals: The Role of Anticipated Future Interaction, Self-Disclosure, and Perceived Success in Internet Dating." Communication Research 33:1-26.

$\rightarrow$ Giles, David C. 2002. "Parasocial Interaction: A Review of the Literature and a Model for Future Research." Media Psychology 4:279-305.

Goffman, Erving. 1959. The Presentation of Self in Everyday Life. Harmondsworth: Penguin.

-1963. Behavior in Public Places: Notes on the Social Organization of Gatherings. New York: Free Press.

. 1981. "Radio Talk." Pp. 197-330 in Forms of Talk, edited by Eriving Goffman. Philadelphia: University of Pennsylvania Press.

$\rightarrow$. 1983. "The Interaction Order." American Sociological Review 48:1-17.

$\rightarrow$ Goodwin, Charles. 1994. "Professional Vision." American Anthropologist 96:606-33.

$\rightarrow$ Griswold, Wendy. 1987. "The Fabrication of Meaning: Literary Interpretation in the United States, Great Britain, and the West Indies." American Journal of Sociology 92:1077-117.

$\rightarrow$ Griswold, Wendy, Erin M. McDonnell, and Terence E. McDonnell. 2007. "Glamour and Honor: Going Online and Reading in West African Culture." Information Technologies and International Development 3:37-52.

$\rightarrow$ Hancock, Jeffrey T., and Philip Dunham. 2001. "Impression Formation in ComputerMediated Communication Revisited: An Analysis of the Breadth and Intensity of Impressions." Communication Research 28:325-47.

Hanks, William. 1996. Language and Communicative Practices. Boulder, Colo.: Westview Press.

$\rightarrow$ Harasim, Linda M., and Tim Winkelmans. 1990. "Computer-Mediated Scholarly Collaboration." Science Communication 11 (4): 382-409.

$\rightarrow$ Haythornthwaite, Carolyn. 2002. "Strong, Weak, and Latent Ties and the Impact of New Media." Information Society 18:385-401. 


\section{Semiotics of E-mail Interaction}

Hedström, Peter, and Richard Swedberg. 1998. "Social Mechanisms: An Introductory Essay." Pp. 1-29 in Social Mechanisms, edited by Peter Hedström and Richard Swedberg. Cambridge: Cambridge University Press.

Herring, Susan, ed. 1996a. Computer-Mediated Communication: Linguistic, Social and Cross-cultural Perspectives. Amsterdam: John Benjamins.

- 1996b. "Two Variants of an Electronic Message Schema." Pp. 81-106 in Computer-Mediated Communication: Linguistic, Social and Cross-Cultural Perspectives, edited by Susan Herring. Amsterdam: John Benjamins.

$\rightarrow \longrightarrow$. 2002. "Computer-Mediated Communication on the Internet." Annual Review of Information Science and Technology 36:109-68.

Hiltz, Starr. 1984. Online Communities. A Case Study of the Office of the Future. Norwood, N.J.: Ablex.

$\rightarrow$ Horton, Donald, and Anselm Strauss. 1957. "Interaction in Audience-Participation Shows." American Journal of Sociology 62:579-87.

Kendall, Lori. 2002. Hanging Out in the Virtual Pub: Masculinities and Relationships Online. Berkeley and Los Angeles: University of California Press.

$\rightarrow$ Kiesler, Sara, and Lee Sproull. 1992. "Group Decision Making and Communication Technology." Organizational Behavior and Human Decision Processes 52:96-123.

$\rightarrow$ Klinenberg, Eric. 2005. "Convergence: News Production in a Digital Age." Annals of the American Academy of Political and Social Science 597:48-64.

$\rightarrow$ Kollock, Peter. 1998. "Social Dilemmas: The Anatomy of Cooperation." Annual Review of Sociology 24:183-214.

- 1999. "The Economies of Online Cooperation: Gifts and Public Goods in Computer Communities." Pp. 109-28 in Communities in Cyberspace, edited by Marc Smith and Peter Kollock. New York: Routledge.

$\rightarrow$ Knorr Cetina, Karin, and Urs Bruegger. 2002. "Global Microstructures: The Virtual Societies of Financial Markets.” American Journal of Sociology 107:905-50.

$\rightarrow$ Kraut, Robert, Ronald E. Rice, Colleen Cool, and Robert S. Fish. 1998. "Varieties of Social Influence: The Role of Utility and Norms in the Success of a New Communication Medium." Organization Science 9:437-53.

Labov, William. 1966. The Social Stratification of English in New York City. Washington, D.C.: Center for Applied Linguistics.

- 1994. Principles of Linguistic Change: Internal Factors. Cambridge, Mass.: Blackwell.

$\rightarrow$ Lamerichs, Joyce, and Hedwig te Molder. 2003. "Computer-Mediated Communication: From a Cognitive to a Discursive Model." New Media and Society 5:451-73.

Latour, Bruno. 1987. Science in Action: How to Follow Scientists and Engineers through Society. Cambridge, Mass.: Harvard University Press.

$\rightarrow$ Lea, Martin, and Russell Spears. 1992. "Paralanguage and Social Perception in Computer-Mediated Communication." Journal of Organizational Computing 2: 321-41.

$\rightarrow$ Lewenstein, Bruce. 1995. "Do Public Electronic Bulletin Boards Help Create Scientific Knowledge? The Cold Fusion Case." Science, Technology and Human Values 2: 123-49.

Ling, Kimberly, et al. 2005. "Using Social Psychology to Motivate Contributors to Online Communities." Journal of Computer-Mediated Communication 10 (4): art. 10. http://jcmc.indiana.edu/vol10/issue4/ling.html.

Mark, Gloria. 2002. "Conventions for Coordinating Electronic Distributed Work: A Longitudinal Study of Groupware Use.” Pp. 259-82 in Distributed Work, edited by Patricia Hinds and Sara Kiesler. Cambridge, Mass.: MIT Press.

$\rightarrow$ Matzat, Uwe. 2004. "Academic Communication and Internet Discussion Groups: Transfer of Information or Creation of Social Contacts?" Social Networks 26:221-55.

$\rightarrow$ McCarty, Willard. 1992. "Humanist: Lessons from a Global Electronic Seminar." Computers and the Humanities 26:205-22. 
American Journal of Sociology

$\rightarrow$ Mesch, Gustavo, and Ilan Talmud. 2006. "The Quality of Online and Offline Relationships: The Role of Multiplexity and Duration of Social Relationships." Information Society 22:137-48.

Meyrowitz, Josh. 1997. "Shifting Worlds of Strangers: Medium Theory and Changes in 'Them' versus 'Us.'" Sociological Inquiry 67:59-71.

Miller, Hugh. 1995. "The Presentation of Self in Electronic Life: Goffman on the Internet." Paper presented at the Conference on Embodied Knowledge and Virtual Space, Goldsmiths College, University of London, June. http://psicopolis.com/ psicopedia/selfweb.htm.

Morris, Charles. 1938. Foundations of the Theory of Signs. Chicago: University of Chicago Press.

. 1946. Signs, Language, and Behavior. New York: Prentice-Hall.

O'Brien, Jodi. 1999. "Writing in the Body: Gender (Re)Production in Online Interaction." Pp. 76-105 in Communities in Cyberspace, edited by Marc Smith and Peter Kollock. New York: Routledge.

Olsen, Mancur. 1965. The Logic of Collective Action: Public Goods and the Theory of Groups. New York: Schocken Books.

$\rightarrow$ Orlikowski, Wanda J. 1996. "Improvising Organizational Transformation over Time: A Situated Change Perspective." Information Systems Research 7:63-92.

$\rightarrow$ Park, Robert. 1938. "Reflections on Communication and Culture." American Journal of Sociology 44:187-205.

Peirce, Charles Sanders. 1934. The Collected Papers of Charles Sanders Peirce, vol. 2. Edited by Charles Hartshorne and Paul Weiss. Cambridge, Mass.: Harvard University Press.

$\rightarrow$ Porter, Steven, and Michael Whitcomb. 2003. "The Impact of Contact Type on Web Survey Response Rates." Public Opinion Quarterly 67:579-88.

$\rightarrow$ Prashantham, Shameen, and Steven Young. 2004. "The Internet and the Internationalisation of Small Knowledge-Intensive Firms: Promises, Problems and Prospects." International Journal of Entrepreneurship and Small Business 1:153-74.

Pudrovska, Tetyana, and Myra Marx Ferree. 2004. "Global Activism in 'Virtual Space': The European Women's Lobby in the Network of Transnational Women's NGOs on the Web." Social Politics 11:117-43.

Rainie, Lee, and John Horrigan. 2005. "A Decade of Adoption: How the Internet Has Woven Itself into American Life." Pew Internet and American Life Project. http:// www.pewinternet.org/PPF/r/148/report_display.asp. Accessed February 15, 2008.

Rezabek, Landra, and John Cochenour. 1998. "Visual Cues in Computer-Mediated Communication: Supplementing Text with Emoticons." Journal of Visual Literacy 18:201-15

Rheingold, Howard. 1993. The Virtual Community: Homesteading on the Electronic Frontier. Reading, Mass.: Addison-Wesley.

Robinson, Laura. 2005. "Debating the Events of September 11th: Discursive and Interactional Dynamics in Three Online Fora." In "Online Communities: Design, Theory and Practice," special issue, Journal of Computer-Mediated Communication 10 (4): art. 4. http://jcmc.indiana.edu/vol10/issue4/robinson.html.

$\rightarrow$. 2007. "The Cyberself: The Self-ing Project Goes Online; Symbolic Interaction in the Digital Age." New Media and Society 9:93-110.

$\rightarrow$ Rosaldo, Michelle Z. 1982. "The Things We Do with Words: Illongot Speech Acts and Speech Act Theory in Philosophy." Language and Society 11:203-37.

Rourke, Liam, Terry Anderson, Randy Garrison, and Walter Archer. 1999. "Assessing Social Presence in Asynchronous Text-Based Computer Conferencing." Journal of Distance Education 14:50-71.

$\rightarrow$ Rice, Ronald. 1992. "Task Analyzability, Use of New Media, and Effectiveness: A Multi-site Exploration of Media Richness." Organization Science 3:475-500.

$\rightarrow$. 1993. "Media Appropriateness: Using Social Presence Theory to Compare 
Traditional and New Organizational Media." Human Communication Research 19: 451-84.

$\rightarrow$ Rice, Ronald, and Gail Love. 1987. "Electronic Emotion: Socioemotional Content in a Computer Mediated Communication Network." Communication Research 14: 85-108.

$\rightarrow$ Ridgeway, Cecilia, and Kristan G. Erickson. 2000. "Creating and Spreading Status Beliefs." American Journal of Sociology 106:579-615.

$\rightarrow$ Ridgeway, Cecilia, and Lynn Smith-Lovin. 1999. "The Gender System and Interaction." Annual Review of Sociology 25:191-216.

$\rightarrow$ Sacks, Harvey, Emanuel Schegloff, and Gail Jefferson. 1974. "A Simplest Systematics for the Organization of Turn-Taking in Conversation." Language 50:696-735.

$\rightarrow$ Sassen, Saskia. 2002. "Toward a Sociology of Information Technology." Current Sociology 50:365-88.

Saussure, Ferdinand de. 1966. Course in General Linguistics. Translated by Wade Baskin. New York: McGraw-Hill.

Schegloff, Emanuel. 2002. "Reflections on Research on Telephone Conversation: Issues of Cross-cultural Scope and Scholarly Exchange, Interactional Import and Consequences." Pp. 249-81 in Telephone Calls: Unity and Diversity in Conversational Structure across Languages and Cultures, edited by Kank Kwong Luke and Theodossia-Soula Pavlidou. Philadelphia: John Benjamins.

Schieffelin, Bambi, and Rachelle Doucet. 1992. "The 'Real' Haitian Creole: Ideology, Metalinguistics, and Orthographic Choice." American Ethnologist 21:176-200.

Schieffelin, Bambi, Kathryn Woolard, and Paul Kroskrity. 1998. Language Ideologies. Oxford: Oxford University Press.

Selwyn, Neil. 2000. "Creating a 'Connected' Community? Teachers' Use of an Electronic Discussion Group." Teacher's College Record 102:750-74.

$\rightarrow$ Severinson Eklundh, Kersten, and Clare Macdonald. 1994. "The Use of Quoting to Preserve Context in Electronic Mail Dialogues." IEEE Transactions on Professional Communication 37:197-202.

Shibutani, Tomatsu. 1978. The Derelicts of Company K: A Sociological Study of Demoralization. Berkeley: University of California Press.

Short, John, Ederyn Williams, and Bruce Christie. 1976. The Social Psychology of Telecommunication. London: John Wiley.

Simmel, Georg. 1921. "Sociology of the Senses." Pp. 356-65 in Introduction to the Science of Sociology, edited by Robert Park and Ernest Burgess. Chicago: University of Chicago Press.

$\rightarrow$ Sproull, Lee, and Sara Kiesler. 1986. "Reducing Social Context Cues: The Case of Electronic Mail.” Management Science 32:1492-1512.

- 1991. Connections: New Ways of Working in the Networked Organization. Cambridge, Mass.: MIT Press.

Thompsen, Philip, and Dong-Keun Ahn. 1992. "To Be or Not to Be: An Exploration of E-Prime, Copula Deletion and Flaming in Electronic Mail." ETC: A Review of General Semantics 49:146-64.

$\rightarrow$ Thompsen, Philip, and Davis Foulger. 1996. "Effects of Pictographs and Quoting on Flaming in Electronic Mail." Computers in Human Behavior 12:225-43.

$\rightarrow$ Treviño, Linda, Jane Webster, and Eric Stein. 2000. "Making Connections: Complementary Influences on Communication Media Choices, Attitudes, and Use." Organization Science 11:163-82

Turkle, Sherry. 1995. Life on the Screen: Identity in the Age of the Internet. New York: Touchstone.

Wallace, Patricia. 1999. The Psychology of the Internet. Cambridge: Cambridge University Press.

$\rightarrow$ Walsh, John P., and Todd Bayma. 1996. "The Virtual College: Computer-Mediated Communication and Scientific Work." Information Society 12:343-63. 


\section{American Journal of Sociology}

Walsh, John P., and Nancy G. Maloney. 2007. "Collaboration Structure, Communication Media, and Problems in Scientific Work Teams." Journal of Computer-Mediated Communication 12 (2): art. 19. http://jcmc.indiana.edu/vol12/ issue $2 /$ walsh.html.

Walther, Joseph. 2002. "Time Effects in Computer-Mediated Groups: Past, Present, and Future." Pp. 235-58 in Distributed Work, edited by Patricia Hinds and Sara Kiesler. Cambridge, Mass.: MIT Press.

$\rightarrow$ Walther, Joseph, and Kyle D'Addario. 2001. "The Impacts of Emoticons on Message Interpretation in Computer-Mediated Communication." Social Science Computer Review 19:323-45.

$\rightarrow$ Walther, Joseph, Geri Gay, and Jeffrey Hancock. 2005. "How Do Communication and Technology Researchers Study the Internet?" Journal of Communication 55:632-57.

$\rightarrow$ Walther, Joseph, Celeste L. Slovacek, and Lisa C. Tidwell. 2001. "Is a Picture Worth a Thousand Words? Photographic Images in Long-Term and Short-Term ComputerMediated Communication." Communication Research 28 (1): 105-34.

Weber, Steven. 2004. The Success of Open Source. Cambridge, Mass.: Harvard University Press.

Weisband, Suzanne. 2002. "Maintaining Awareness in Distributed Team Collaboration: Implications for Leadership and Performance." Pp. 311-33 in Distributed Work, edited by Patricia Hinds and Sara Kiesler. Cambridge, Mass.: MIT Press.

Wellman, Barry, et al. 2006. "Connected Lives: The Project." Pp. 1-50 in Networked Neighbourhoods, edited by Patrick Purcell. London: Springer.

Wellman, Barry, and Carolyn Haythornthwaite. 2002. The Internet in Everyday Life. Oxford: Blackwell.

$\rightarrow$ Wheelan, Susan A., and Robert M. Kaeser. 1997. "The Influence of Task Type and Designated Leaders on Developmental Patterns in Groups." Small Group Research 28:94-121.

Williams, J. Patrick, and Heith Copes. 2005. "'How Edge Are You?' Constructing Authentic Identities and Subcultural Boundaries in a Straightedge Internet Forum." Symbolic Interaction 28:67-89.

$\rightarrow$ Winkielman, Piotr, Barbel Knauper, and Norbert Schwartz. 1991. "Looking Back at Anger: Reference Periods Change the Interpretations of Emotion Frequency Questions." Journal of Personal Social Psychology 75:719-28.

Yamigishi, Toshio. 1995. "Social Dilemmas." Pp. 311-35 in Sociological Perspectives on Social Psychology, edited by Karen Cook, Gary Alan Fine, and James House. Boston: Allyn \& Bacon.

$\rightarrow$ York, Erin, and Benjamin Cornwell. 2006. "Status on Trial: Social Characteristics and Influence in the Jury Room." Social Forces 85:455-77.

Zhao, Shanyang. 2004. "Consociated Contemporaries as an Emergent Realm of the Lifeworld: Extending Schutz's Phenomenological Analysis to Cyberspace." Human Studies 27:91-105. 